\title{
LAPORAN KASUS \\ Penatalaksanaan Anestesi Pada Total Anomalous Pulmonary Venous Drainage
}

\section{Anesthetic Management in Total Anomalous Pulmonary Venous Drainage}

Bagus Damar Ririh Wiyatmoko*, Chairil Gani Koto*

*Rumah Sakit Pusat Jantung Harapan Kita

\section{ABSTRACT}

Background : TAPVD is one of cyanotic congenital heart disease. There is no connection between pulmonary vein and left atrium; pulmonary vein was directly drain into right atrium or systemic vein (innominate, superior cava, Azygus, inferior cava or portal vein) through alternative ways (vertical vein). All venous blood drain into right atrium, thus the patient life depend on the connection between left and right atrium.

Case: 12 years old boy with major complain exhausted and weight gain difficulty. Echocardiography show supracardiac TAPVD (to innominate vein), large ASD (right to left shunt), mild tricuspid regurgitation and moderate pulmonary hypertension. Anesthetic management aimed to reduce pulmonary blood flow through controlled ventilation dan quick extubation after repair procedure was finished. Central venous pressure, arterial line and pulmonary arterial pressure monitoring is very useful. Perioperative pulmonary hypertension could be treated with hyperventilation, oxygenation, alkalinization, deep sedation dan muscle relaxant.

Keywords: Total Anomalous Pulmonary Venous Drainage, congenital heart disease, anesthesia

\section{ABSTRAK}

Pendahuluan: TAPVD merupakan salah satu CHD yang bersifat sianotik. TAPVD merupakan anomali vena paru kongenital yang mana tidak ada hubungan antara pembuluh darah paru dan atrium kiri; vena paru terhubung langsung ke atrium kanan atau ke vena sistemik (inominata, vena cava superior, Azygus, vena cava inferior atau vena portal) oleh jalur alternatif(vena vertikal). Karena semua darah vena kembali ke atrium kanan, sehingga kelangsungan hidup penderita tergantung pada koneksi antara atrium kiri dan kanan.

Kasus: Anak laki-laki 12 tahun dengan keluhan cepat lelah dan berat badan sulit naik. Ekokardiografi menunjukkan adanya TAPVD supracardiac (ke V.inominata), ASD besar (pirau kanan ke kiri), TR mild dan PH moderate. Prinsip manajemen anestesi dengan mengurangi aliran darah ke paru melalui kontrol ventilasi dan pertimbangkan ekstubasi cepat setelah repair. Monitoring dengan CVP, LA pressure dan PA pressure sangat membantu. Hipertensi pulmonal perioperatif ditangani dengan hiperventilasi, oksigen 100\%, alkalinisasi, sedasi dalam dan pelumpuh otot.

Kata kunci: Total Anomalous Pulmonary Venous Drainage, penyakit jantung bawaan, anestesi 


\section{PENDAHULUAN}

Kelainan jantung bawaan (Congenital heart disease, $\mathrm{CHD}$ ) relatif jarang terjadi, diperkirakan $<1 \%$ dari kelahiran hidup. Pada awal kelahiran beberapa CHD asimtomatik. ${ }^{1}$ CHD merupakan kelainan jantung yang sudah didapat sejak lahir. Manifestasinya klinis bergantung dari berat ringan penyakit, mulai dari asimtomatis sampai dengan adanya gejala gagal jantung pada neonatus. Dengan berkembangnya teknologi, terutama dengan ditemukannya ekokardiografi, banyak kelainan jantung bawaan asimtomatis yang dapat dideteksi. Tata laksana meliputi non-bedah dan bedah. Tata laksana non-bedah meliputi pengobatan medikamentosa dan kardiologi intervensi, sedangkan tata laksana bedah meliputi bedah paliatif dan operasi definitif. $^{2}$ Salah satu bentuk CHD yang jarang terjadi yaitu Total Anomalous Pulmonary Venous Drainage (TAPVD) atau dikenal juga dengan Total Anomalous Pulmonary Venous Connection (TAPVC) atau Total Anomalous Pulmonary Venous Return (TAPVR). ${ }^{3-6}$

TAPVD merupakan salah satu CHD yang bersifat sianotik, insiden sebesar $0,008 \%$ dari kelahiran hidup, atau sebesar 2,2\% dari CHD. TAPVD merupakan anomali vena paru kongenital yang mana tidak ada hubungan antara pembuluh darah paru dan atrium kiri; vena paru terhubung langsung ke atrium kanan atau ke vena sistemik (innominate, vena cava superior, Azygus, vena cava inferior atau vena portal) oleh jalur alternatif (vena vertikal). Karena semua darah vena kembali ke atrium kanan, sehingga kelangsungan hidup bayi tergantung pada koneksi antara atrium kiri dan kanan. ${ }^{5}$

\section{KASUS}

Anak laki-laki 12 tahun dengan keluhan cepat lelah dan berat badan sulit naik. Merupakan rujukan dari daerah dengan diagnosis atresia aorta. Pemeriksaan fisik pre operasi ditemukan tanda vital normal, saturasi pre operasi $94 \%$ dan peningkatan suara jantung 2 dengan wide fixed split tanpa murmur atau gallop. Hasil laboratorium hematologi dalam batas normal, ronsen thorax ditemukan pinggang jantung datar, dan hasil ekokardiografi ditemukan TAPVD supracardiac (ke V.inominata), ASD besar (R-L shunt), TR mild dan $\mathrm{PH}$ moderate.

Pasien ini kemudian didiagnosis TAPVD supracardiac, ASD besar dan PJB asianotik.

Dilakukan anestesi dengan premedikasi midazolam, induksi dengan sufentanyl $10 \mu \mathrm{g}$ dan vecuronium $2 \mathrm{mg}$. Pemeliharaan dengan sevoflurane $1 \%$ volume dalam $\mathrm{O}_{2}$ : air $=50 \%: 50 \%$. Sufentanyl dan vecuronium bolus intermitten. Monitoring invasif dengan arterial line, central venous catheter (CVC) dan pulmonal artery line. 
Support selama operasi dengan milrinon $0,375 \mu \mathrm{g} / \mathrm{kgBB} / \mathrm{menit}$ dan NTG $1 \mu \mathrm{g} /$ $\mathrm{kgBB} /$ menit. Durasi CPB selama 112 menit, aorta cross clamp 55 menit dan balans cairan -305 .

\section{PEMBAHASAN}

TAPVC dibagi menjadi empat tipe: supracardiac, cardiac, infracardiac, dan campuran. Prinsip perbaikan operasi adalah membuat hubungan antara vena paru dan atrium kiri, hubungan dengan sirkulasi vena sistemik, dan menghapus shunting intracardiac. Perbaikan yang spesifik tergantung pada jenis koneksi anomali. Obstruksi vena pulmonalis merupakan komplikasi yang signifikan dan komplek. ${ }^{4}$

TAPVD terbagi atas : ${ }^{4,5}$

Tipe-I: TAPVD melibatkan drainase ke dalam sistem vena sistemik melalui sisi kiri vertikal vena (suatu sisa embryologic dari sistem kardinal kiri), yang mengalir ke kiri brakiosefalika vena atau langsung ke vena kava superior. Terjadi pada $46 \%$ dari pasien yang memiliki TAPVD. Insiden: $46 \%$ dari total kasus.

Tipe II: Ini melibatkan drainase langsung ke jantung, biasanya melalui sinus koroner atau langsung ke dalam atrium kanan. Insiden-26\% dari total kasus.

Tipe III: Ini melibatkan drainase melalui vena descending di bawah diafragma dan bergabung dengan vena cava inferior, vena hepatica, atau sistem portal. Tipe ini biasanya terjadi obstruksi dari aliran balik vena paru. Insiden: $24 \%$ dari total kasus.

Tipe IV, Sangat jarang, melibatkan beberapa drainase. Insiden: approx 5\% dari total kasus.

Pada pasien ini termasuk dalam TAPVD tipe I, dimana semua vena pulmonalis ke vena innominata kemudian ke vena cava superior dan secara klinis merupakan unobstructed TAPVD karena adanya ASD yang besar.

Gambaran klinis : ${ }^{5}$

Timbulnya gejala: Kebanyakan pasien mengalami gejala dalam 1 tahun kehidupan: takipnea, kesulitan makan, sering infeksi pernafasan, dan gagal tumbuh.

Awitan awal gejala: Pasien yang memiliki obstruksi vena pulmonalis dapat terjadi dalam hari-hari pertama kehidupan dengan takipnea, sianosis, dan gagal jantung.

Temuan Klinis Klasik : 5

Unobstructed TAPVD: ditemukan Klasik ASD - split lebar dan suara jantung kedua tetap dengan S3 RV ejeksi dan murmur ejeksi sistolik pada bayi yang mengalami gagal jantung kongestif dan sianosis sehingga harus meningkatkan kecurigaan TAPVD.

Obstructed TAPVD: biasanya pada TAPVD, darah dari vena pulmonalis butuh waktu lebih lama untuk mencapai atrium kiri. Jalur ini mungkin hanya 
Tabel 1. Skematik TAPVD

\section{Tipe I}

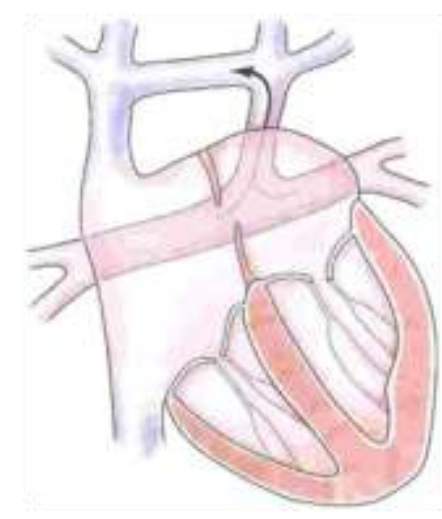

Supracardiac TAPVC: common vein ke dalam vena innominate atau vena kava superior melalui vena vertikalis

\section{Tipe II}

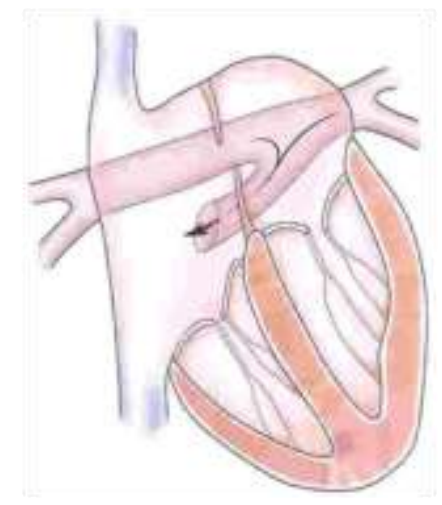

Cardiac TAPVC: vena pulmonalis ke dalam sinus koroner atau, pada keadaan tertentu vena pulmonalis akan terhubung langsung ke atrium kanan.

Tipe III

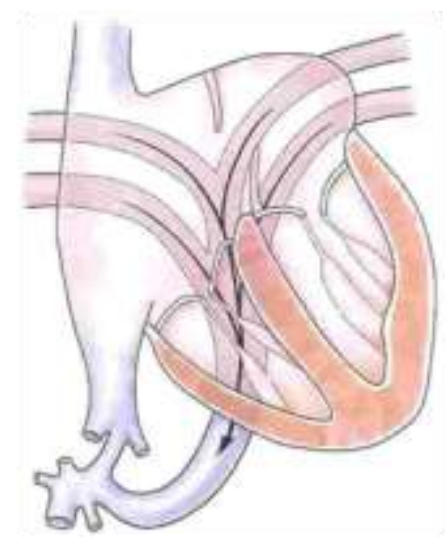

Infracardiac TAPVC: saluran vena pulmonalis melalui diafragma ke dalam vena portal atau duktus venosus. 
terbatas di tempat-tempat seperti di tingkat koneksi interatrial atau drainase ke vena vertikalis secara ascending maupun descending yang mengakibatkan peningkatan tekanan vena pulmonalis dan penurunan cardiac output. Diagnosis ini harus dicurigai pada neonatus yang sangat sianosis dengan CHF.

Foto thorak $x$-ray: Pada jenis unobstructed TAPVD, biasanya terdapat hipertrofi ventrikel kanan dan atrium kanan dengan peningkatan aliran darah paru. Pada pasien yang mempunyai aliran balik ke vena brakiosefalika kiri, mungkin ada pembesaran mediastinum superior, bilateral dalam bentuk angka-8 atau salju. Hasil elektrokardiogram biasanya akan menunjukkan kelainan right-axis deviasi dengan right atrial $P$ gelombang dan hipertrofi ventrikel kanan. Obstructed TAPVD dapat dengan ukuran jantung yang relatif normal dan adanya hipertensi vena pulmonal, ground glass opacity. ${ }^{5}$

Ekokardiografi: Dua-dimensi echocardiography dapat menetapkan diagnosis dengan lebih akurat. ${ }^{5}$ CT Angio/ kateterisasi konvensional: mungkin diperlukan jika echocardiography belum meyakinkan dalam menentukan tempat koneksi vena paru. $^{5}$

Pengobatan: Diagnosis TAPVD merupakan indikasi untuk operasi jantung terbuka. Proses pembedahan tergantung letak kelainan.
Komplikasi morbiditas utama yang terjadi pasien pasca operasi: ${ }^{5}$

Post-repair pulmonary venous obstruction perlu intervensi ulang; Pulmonary vein stenosis biasanya tidak terdeteksi sebelum operasi; Late arrhythmias seperti disfungsi sinus node, termasuk sinus bradikardia, penurunan kemampuan chronotropic pada sebagian besar pasien setelah 10 tahun pasca operasi.

\section{Patofisiologi}

Sebagai hasil dari campuran aliran vena pulmonal dan sistemik, di atrium kanan dan ventrikel kanan terjadi peningkatan volume pada semua pasien dengan anomali vena paru. Jika foramen ovale tertutup, tekanan atrium kanan meningkat, terjadi kongesti vena sistemik dan paru. Meningkatkan aliran darah paru, dan hipertensi arteri pulmonalis mungkin terjadi. Atrium kiri dan ventrikel kiri menerima aliran kurang dari normal dan pompa kurang dari volume normal, dengan beberapa penurunan indeks jantung. Kebanyakan pasien dengan total anomali paru memiliki foramen ovale paten dengan beberapa tingkat pembatasan mengalir trans-atrial. Jika tidak ada obstruksi vena paru, meningkatkan aliran darah paru (misalnya, 3-5 kali volume sistemik) di awal masa bayi, dan saturasi oksigen arteri dipertahankan, biasanya pada $90 \%$ atau lebih tinggi. Tanda-tanda volume jantung beban kanan atau gagal jantung kanan yang jelas. 

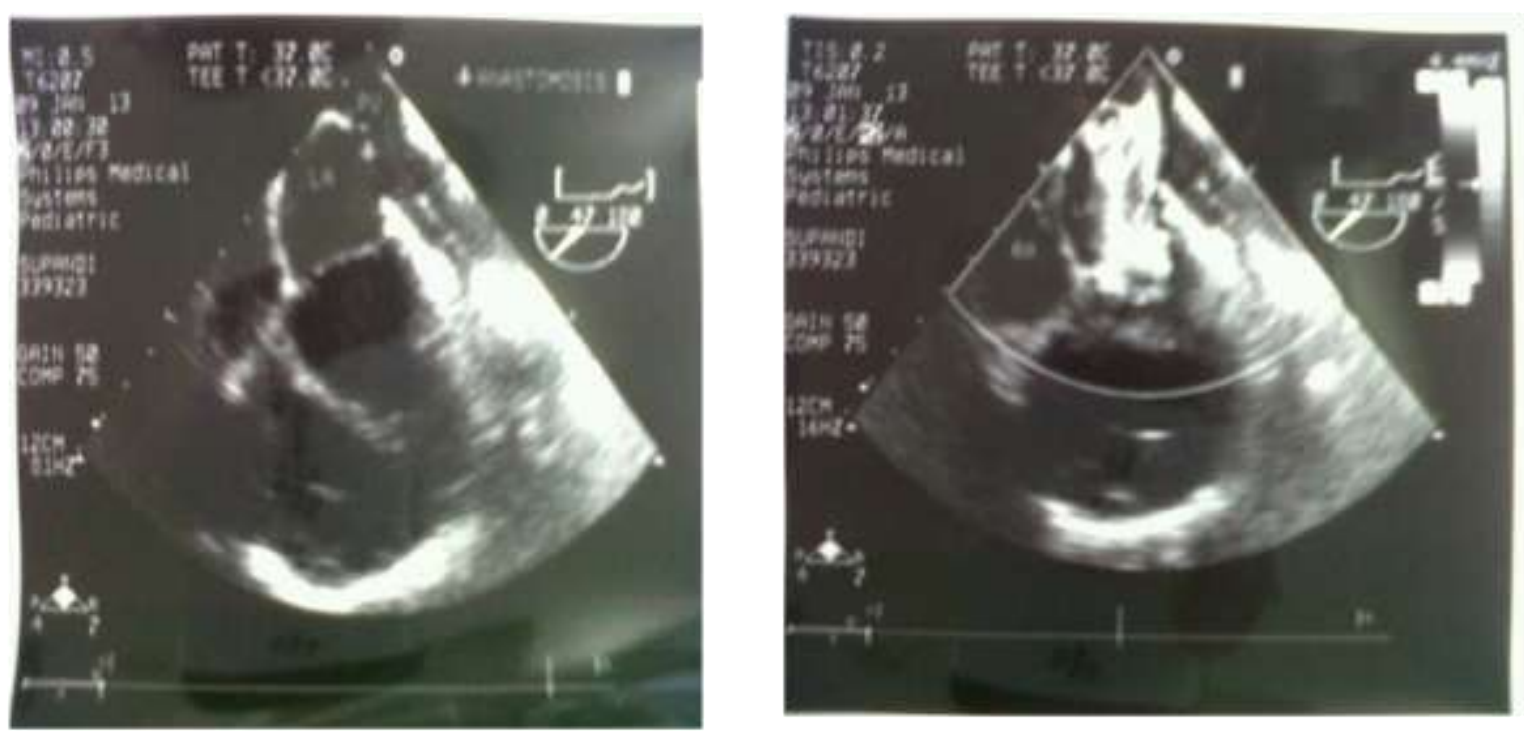

Gambar 1. View TEE setelah repair TAPVD,tampak drainase vena pulmonalis ke atrium kiri.

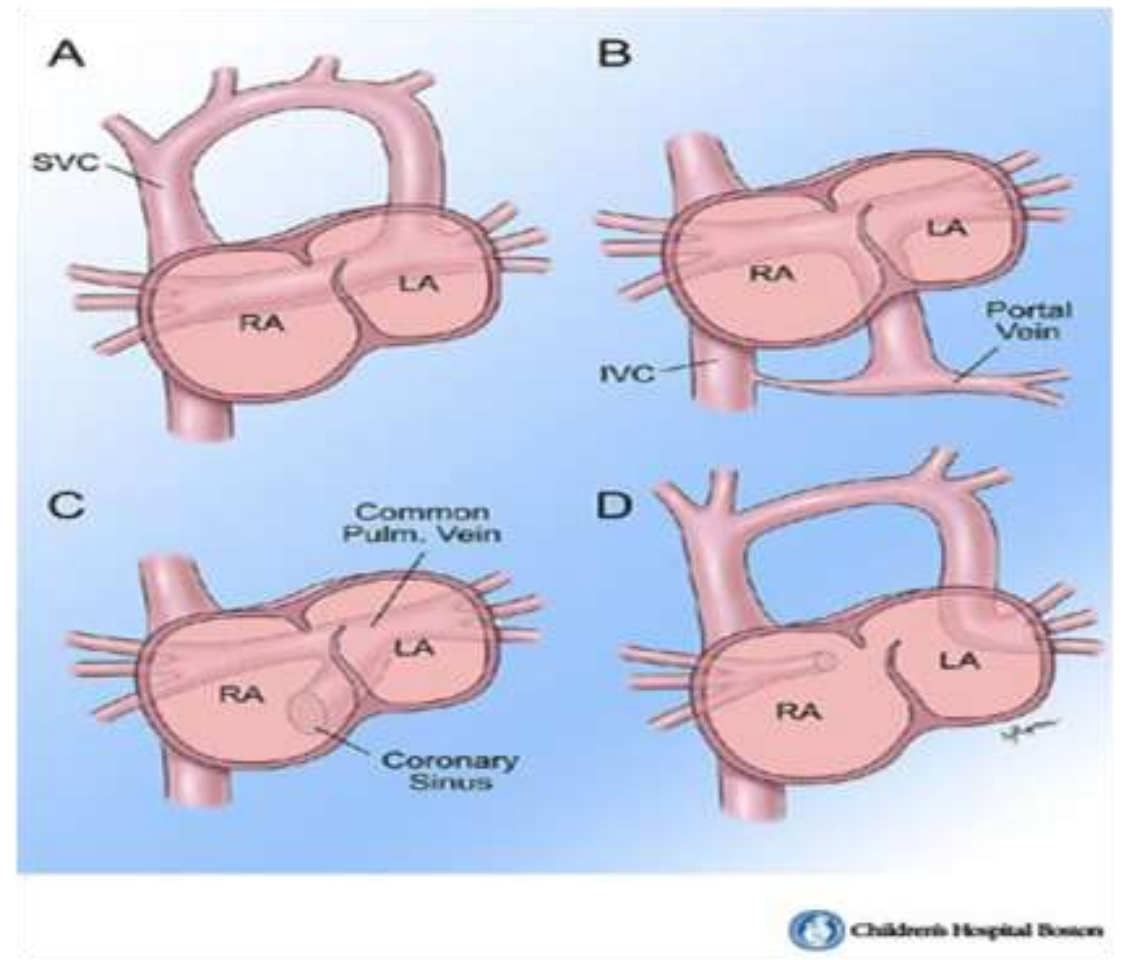

Gambar 2. Empat jenis utama TAPVD, ditandai oleh adanya aliran darah dari pembuluh darah paru ke atrium kanan oleh vena masuk dari atas, bawah, di tingkat jantung atau kombinasi. Untuk masing-masing jenis, ada hubungan atrium yang memungkinkan darah untuk mencapai sisi kiri jantung. TAPVD biasanya mempunyai cacat jantung lain yaitu defek septum atrium (Atrial septal defect, ASD). ${ }^{6}$ 
Jika terjadi obstruksi vena pulmonalis, kongesti vena pulmonalis kemudian terjadi dengan akibat aliran limfatik paru pun meningkat dan peningkatan aliran melalui jalur vena alternatif paru. Vasokonstriksi arteri Reflex paru juga dapat terjadi. Peningkatan resistensi vaskuler paru menyebabkan penurunan aliran darah paru dan volume yang lebih rendah dari darah yang jenuh dalam campuran vena. Penurunan saturasi oksigen sistemik bersama dengan penurunan indeks jantung dapat menyebabkan penurunan yang parah dalam pengiriman oksigen. ${ }^{7}$

\section{Manajemen Anestesi}

Pertimbangan intraoperatif pada pasien dengan PAPVD/ TAPVD hampir mirip dengan penatalaksanaan pasien dengan ASD, karena adanya peningkatan aliran darah ke paru. Mengurangi aliran darah ke paru dengan mengontrol ventilasi dan mempertimbangkan untuk ekstubasi secara cepat setelah dilakukannya repair merupakan tujuan utama pada pasien ini.

Penatalaksanaan pre-bypass pada pasien dengan dengan obstructed TAPVD dengan cara meningkatkan $\mathrm{PO}_{2}$, memperbaiki asidosis metabolik yang terjadi, dan mempertahankan kestabilan hemodinamik dengan obat-obatan inotropik yang dibutuhkan. Transesophageal echocardiography biasanya merupakan kontraindikasi karena dapat menyebabkan penekanan dan obstuksi pada vena pulmonalis meskipun pada jenis non-obstructed
TAPVD. Monitoring dengan menggunakan $C V P$, LA pressure dan $P A$ pressure mungkin akan sangat membantu.

Setelah periode bypass, NO harus digunakan secara empiris untuk manajemen obstructed TAPVD dan harus tersedia juga untuk yang nonobstructed TAPVD jika sewaktu waktu diperlukan. Hipertensi pulmonal terjadi pada lebih kurang 50\% pasien TAPVD dan merupakan resiko mayor terjadinya kematian dini. Krisis hipertensi pulmonal dapat dihindari dengan melakukan hiperventilasi, pemberian oksigen 100\%, alkalinisasi, sedasi, pemberian pelumpuh otot. Magnesium sulfat dan prostaglandin $\mathrm{E}_{1}$ telah banyak digunakan untuk mengobati hipertensi pulmonal yang berat. ${ }^{8}$

Fungsi paru setelah periode bypass kadang belum membaik akibat (i) adanya edema pulmonum preoperatif akibat efek sekunder dari obstruksi vena dan (ii) akibat respon inflamasi akibat CPB. Komplain paru menurun dan gradien arterial-alveoli menjadi besar, fungsi paru dapat diperbaiki dengan memberikan pressure control ventilation dan PEEP untuk meningkatkan komplians paru. ${ }^{8}$

Setelah repair, tekanan di atrium kiri mungkin akan meningkat akibat aliran darah dari vena pulmonalis kembali ke atrium kiri,dimana sebelum repair, atrium kiri cenderung berukuran lebih kecil dan ventrikel kiri yang komplainnya kurang. Ketika weaning 
dari CPB diusahakan agar tekanan darah tidak terlalu tinggi untuk menghindari overdistended sisi kiri jantung. Pemberian cairan harus hatihati dengan mengoptimalkan irama jantung dan denyut jantung dan pemberian inotropik akan meningkatkan cardiac output. ${ }^{8}$ Selain itu bisa juga dengan pemberian obat inodilator seperti milrinon yang dapat menurunkan left ventricular work dan juga meningkatkan cardiac output.

\section{RINGKASAN}

Manajemen anestesi untuk pasien dengan TAPVD: 1. Maksimalkan oksigenasi dengan ventilasi mekanik, FiO2 100\% dan tindakan lain untuk menurunkan PVR; 2. Hipertensi pulmonal perioperatif sering membutuhkan hiperventilasi, oksigen $100 \%$, alkalinisasi, sedasi dalam dan pelumpuh otot; 3 . Hindari penggunaan TEE yang dapat memperburuk obstruksi vena pulmonalis; 4. Hindari pemberian cairan yang berlebihan pada jantung kiri; 5. Pemberian obat inotropik, inodilator; 6. Diagnosis dan obati bila ada gangguan irama jantung.

\section{DAFTAR PUSTAKA}

1. Laurie K, Daniel KG. Anaesthetic management for Congenital Heart Disease. In: Hensley AF, Martin ED, Gravlee PG, eds. Lippincott Williams \& Wilkins. 5th ed. 2012: p. $375-438$

2. Mulyadi M, Bambang M. Tatalaksana Penyakit Jantung Bawaan. Sari pediatric 2000; 2(3): 155-62

3. Sohsuke Y, Masanori H, Ke-Yong W, Yan Ding, Xin Guo, Shohei Shimajiri, et al. Total anomalous pulmonary vein drainage: Report of an autopsy case associated with atresia of the common pulmonary vein and left superior pulmonary vein. Pathology Internationale 2011; 61: 93-8

4. Jennifer $\mathrm{CH}$, Edward L.Total anomalous pulmonary venous connection.. European Association for Cardio thoracic surgery 2007; $1-7$

5. CME: Total Anomalous pulmonary venous Drainage(TAPVD). Cited in : 25-1-2013.

Available from URL : http:// www.cardioiap.org/PDF/TAPVD.pdf

6. Boston children hospitals. Anomalous pulmonary venous return (TAPVR or PAPVR). Cited in 26-1-2013. Available from URL : http:// www.childrenshospital.org/az/Site475/ mainpageS475P1.html

7. Allen DW. Total Anomalous Pulmonary Venous Connection. Cited in 27-1-2013. Aailable from URL : http:// emedicine.medscape.com/article/899491overview\#a0104

8. Dean BA, Stephen AS, Isobel AR. Anesthesia for congenital heart disease. 2005. pg 310-314 